\title{
Integrated energy efficient cooling solutions for large prefabricated panels collective dwellings from the 1970s
}

\author{
Marius Adam ${ }^{1}$, Daniel M. Muntean ${ }^{2,}$, Miodrag Popov ${ }^{3}$, Daniel Grecea ${ }^{2,4}$ and Viorel Ungureanu ${ }^{2,4}$ \\ ${ }^{1}$ Politehnica University Timisoara, Department of Civil Engineering and Building Services, 300223 Traian Lalescu 2A, Romania \\ ${ }^{2}$ Politehnica University Timisoara, Department of Steel Structures and Building Mechanics, 300224 Ioan Curea 1, Romania \\ ${ }^{3}$ Politehnica University Timisoara, Department of Architecture, 300223 Traian Lalescu 2A, Romania \\ ${ }^{4}$ Romanian Academy, Timisoara Branch, 300223 Mihai Viteazu 24, Romania
}

\begin{abstract}
The intense urbanization process Romania has known during the industrialization period of the 1960-70s led to an exponential shortage in urban housing. Similar to other countries, but more specifically to the former Eastern block, Romanian state-financed collective dwellings were erected starting from standardized projects of Reinforced Concrete Large Prefabricated Panels (RCLPP) blocks of flats, generating nowadays a particular built stock of identical buildings and several apartment types, widespread throughout the entire country. These buildings currently house $60 \%$ of the urban population of Romania that own $96 \%$ of the apartments, as opposed to the European trends regarding the number of owner-occupied barely reaching $60 \%$. Even though at not even half of their intended lifespan, the collective dwellings do not satisfy basic comfort conditions such as cooling and ventilation, being in an urge of retrofitting and upgrading. Individually applicable cooling systems undertaken by the owners have proved to be acceptable, but did not, however, contribute to a decrease in the overall energy consumption of the buildings. The present paper analyses the individual cooling systems being currently applied in Romanian apartments as opposed to a global-holistic system on block level, in terms of energy consumption and efficiency, flexibility of owner controlled indoor microclimate. The results show the potential of introducing renewable energy sources as viable alternatives for the existing systems.
\end{abstract}

\section{Introduction}

The industrialization period had a major impact on the existing urban environment. The urban population has significantly increased. New homes had to be created in a short time to accommodate the workers coming from the rural areas in hope of a better life. Architecture project-types using Reinforced-Concrete Large Prefabricated Panels (RCLPP) were implemented to reduce construction time and rapidly meet the increased housing demands. It resulted a repetitive pattern that could be applied in multiple ways according to the urban limits [1]. These so called "match boxes", because of their small dimensions, have been built extensively throughout the Eastern block. The technology of building using RCLPP has been applied in the northern European countries as well. Although the technology was similar, these buildings have managed to be optimized towards sustainability [2].

Today, the topic of existing building retrofitting, especially applied on those from the east-European areas has become a concern as well as a necessity world-wide for ensuring optimal parameters towards sustainable development. Because these buildings were used on such a wide scale and sheer numbers, upgrading them to the current standards, instead of demolishing them is the best economical solution [3].

Today the overall qualities that these buildings once had, have degraded. They are no longer able to satisfy the modern living standards. Although rehabilitation programs have been initiated, they are few and only offer partial and uncoordinated solutions [6]. For cooling service systems, the improvements were minimal. Because of the high number of apartment owners, individual cooling systems using splits were chosen, usually mounted within closed balconies or on the facades of the buildings.

This paper presents the benefits of introducing alternative renewable cooling systems by comparing them with the existing individual ones. The new system offers a passive adiabatic cooling option connected to a heat recovery system for improved energy efficiency. The necessary piping is installed within a ventilated façade system and a renewable cooling system in form of a "Canadian shaft" is integrated.

\footnotetext{
* Corresponding author: daniel.m.muntean@gmail.com
} 


\section{The collective housing stock in Romania. Model T770}

\subsection{Model T770 characteristic}

In Romania, the buildings out of RCLPP represent $1,8 \%$ of the entire building stock and houses more than half of the country's population [4]. Although similar with the dwelling typologies from the Western Europe, these blocks of flats have different characteristics and background. Design for disadvantaged people was not a considered factor. They were simply seen as the only new housing option.

Compared to the rest of Europe, between 1961 and 1990 Romania had one of the highest percentages of RCLPP units being build (60\%), with Ireland (32\%) and Estonia $(80 \%)$ at both ends of the list. However, if the number of apartments, being occupied by owners, Romania leads with $96 \%$, with $4 \%$ tenants compared to Switzerland with $65 \%$ tenants. More so, the ratio between square meter available to each person, Romanian collective housing allocates $20 \mathrm{~m}^{2} /$ person while South and North Western Europe providing 31 $\mathrm{m}^{2} /$ person and $36 \mathrm{~m}^{2} /$ person respectively [5].

One of the most common RCLPP building typology is the T770 (Figure 1). This 5-storey residential unit was built extensively all over the country during the 70 s and offered the lowest building comfort conditions.
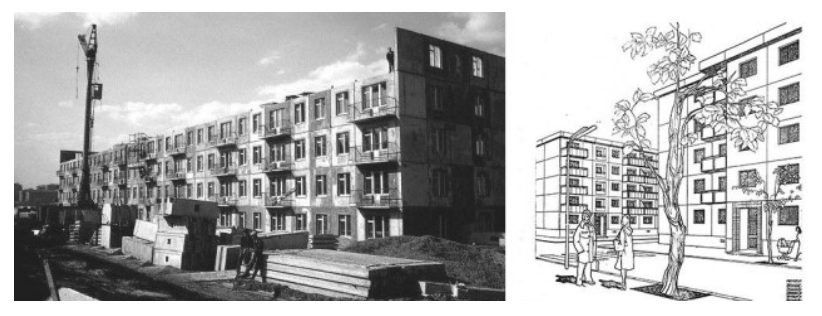

Fig. 1. Model T770.

The infrastructure consists of a strip foundation under the structural walls out of concrete B75 (C4/5). The width of the foundation varies depending on the block typology, because the conventional pressure is different in all zones. Foundation elevations (basement) are made of $20 \mathrm{~cm}$ thick cast-in-place reinforced concrete B150 (C8/10) [6]. The superstructure is made entirely of precast panels, $14 \mathrm{~cm}$ bearing reinforced concrete B200 $(\mathrm{C} 12 / 15)$ panels used in the interior upper storeys respect a maximum weight of 5.1 tones because, a lifting restraint of the used crane model MT110 at that time. The exterior wall panels are made of 2 layers of concrete B250 (C16/20) and a thermal insulation layer of CBA, all within a total width of $30 \mathrm{~cm}$. The slabs are made of reinforced concrete panels and have a width of $13 \mathrm{~cm}$.

The wall reinforcement consists of PC52 type (S355 grade) for $10 \mathrm{~mm}$ longitudinal 97 bars and for $14 \mathrm{~mm}$ vertical continuity bars and STPB type (S490) for $4 \mathrm{~mm}$ welded wire mesh. The ultimate cubic compressive strength of concrete for the tested and modelled wall panel is 17.5 MPa [7]. Joints between the panels were assured by welding the concrete steel reinforcements and B300 (C18/22.5) quality concrete in-place casting.

\subsection{The private property - a challenge?}

In Romania, one should mention that during the Soviet regime, the notion of private property as in the liberal doctrine was replaced by the propiska (translated as subscriptions). In the case of state-owned collective dwellings, the propiska only had the role of temporary or permanent residential permits that could not be inherited by other family members. The State also owned all urban lands and while building a private-owned urban house was also possible, an annual rent on the land it sited on was charged. After the 1990s, all former states of the Soviet Union have allowed a private ownership of the state properties.

In spite of this, as a result of a different political vision in Romania, forms of private property was allowed and guaranteed by the state offered by the state as early as the 1970s. Although many of the collective dwellings were still built by the state, the independent flats started to be sold to individual private owners by means of a state-crediting system. After 1989, the depreciation of the national currency further increased the affordability of the flats, allowing most of the people the repayment of their credits and others to massively buy the apartments they lived in already, placing Romania as the European country with the most owneroccupied homes. The fact that these flats were not also independent from a technical point of view will prove a major difficulty on all future plans of retrofitting this particular built stock According to the Romanian legislation today, the collective dwellings fall in the incidence of two main types of private property, as follows:

- $\quad$ private property: the flats in themselves, where the owner, in almost all cases, the occupant himself, is the sole deciding factor for any interventions;

- non-divisible common property: all the common spaces (the staircase, the rooftop), building services (piping network), the building facade and a perimeter area of 0.9 meters around the entire building, belonging to all of the inhabitants; these cannot be divided into proportional separate parts and on which the deciding factor on any intervention is the majority of the owners, the occupants themselves.

Apart from the National Thermal Rehabilitation Program that also affects the collective dwellings, providing with a shallow improvement of the thermal envelope and the decrease of heating energy requirements via the addition of a EPS layer of thermal insulation and the replacement of the openings with PVC joinery and double glass insulated panels, no other significant improvement was obtained. Due to the particular conditions regarding the property, all global intervention schemes so far that cross both non-divisible and private property, top-bottom interventions that could offer significant funding opportunities depend by the owners' ballot, in which case, the veto right means that the intervention will not take place. 


\subsection{An integrated architectural and structural approach for retrofitting the RCLPP collective dwellings}

An alternative intervention for retrofitting these collective dwellings is proposed, based on a limited and flexible use of the façade of the buildings. An integrated solution was considered, in the form of a reversible, 380 $\mathrm{mm}$ ventilated façade system, capable of accommodating a supplementary insulation layer and new heating and cooling system on the exterior of the block of flats. The main advantage lies in the distribution of a main piping system within the limits of the non-divisible property, with minimum interfering with the private property of the apartments, which can subsequently connect to the system, at any given time.

The solution offers a long-term advantage for all the apartments and can achieve significant increase in energy efficiency allowing good return of investment periods and opening new possibilities towards ESCo type financing models.

\subsection{Global structural assessment of the proposed solution}

Due to the narrow area around the building that does not always allow new foundations, the proposed ventilated façade intervention considered the hypothesis of independently attaching the new façade onto the existing building. The proposed structural solution, therefore, will take into consideration the characteristics of the LPRCP applied to model 770 , as described in the previous paragraphs.

Since the presence of the intermediate spaces in dense urban areas (e.g. balconies, terraces, loggias) directly influence the quality of life, as recent studies have shown, the solution also allows the addition of prefabricated steel structure modules at any level of an existing block of flats [9] The proposed solution consists of a vertically placed HEA260 castellated column pinned at façade level, as Figure 3 shows. Using a base plate welded to the flange of the profile, the vertical beam is attached to the existing façade of the building by 4 steel L-shaped $(160 \times 160)$ counterpieces and $4 \times$ M16 steel rods, at each intersection between the slab and façade panels, locally reinforcing the monolithic connection between the existing RCLP panels.

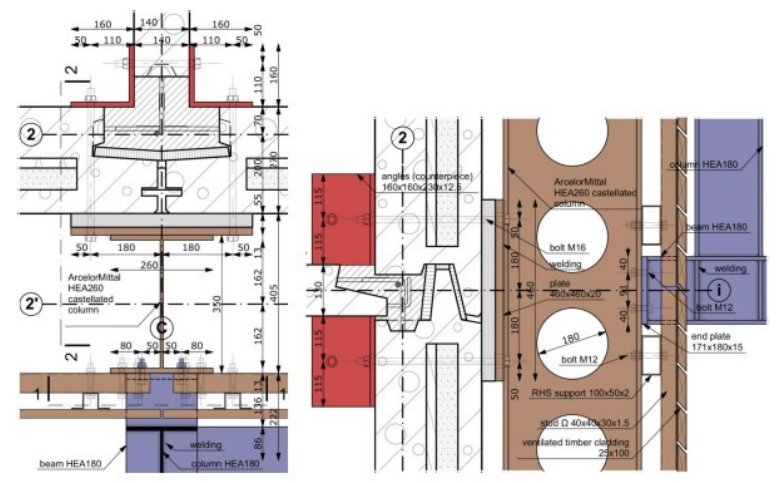

Fig. 2. Connection detail for the ventilated façade.
The total space obtained reaches $380 \mathrm{~mm}$, while allowing the thermal insulation layer and the new piping system to coexist behind the ventilated façade.

In the period 1965-1975 until now, several changes of the codes for actions and structural design codes have appeared. Due to the fact that it was intended to be built in the entire country, the initial 770 project, designed according to the former seismic codes, only recommended different reinforcements in the monolithic areas at the connection between the prefabricated panels, depending on the location of the building, leaving the RCLPP the same for all seismic areas The general strategy in evaluating such interventions on existing buildings demands the following steps: (i) structural analysis of existing building in order to prove the structure capability, to comply the actual design and (ii) structural analysis including the extensions, considering several scenarios. An example of such analysis is given below by considering 3D analyses using ETABS computer code the case of building type $770 \mathrm{~Pa} 2$ [9]. Shell finite elements for simulating the concrete panels (both horizontal and vertical) and beam elements for the proposed ventilated facade solutions have been used.

Table 1. Global structural analysis of the impact of the ventilated façade.

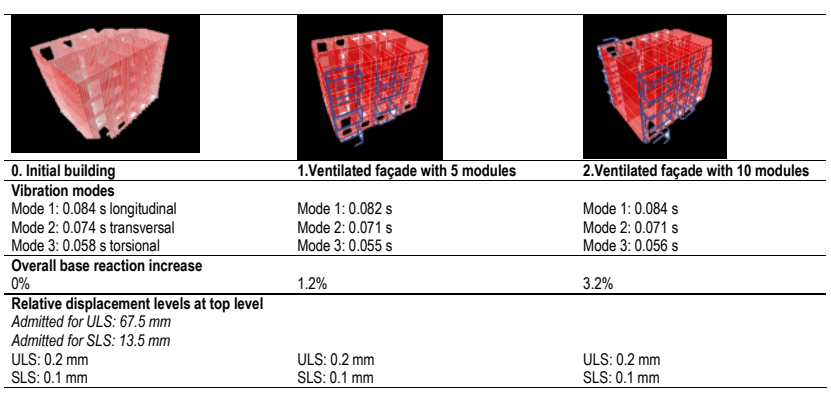

\section{Apartment ventilation during summer}

\subsection{Context}

Currently all apartments are using splits system ventilation during the summer. These systems have some major disadvantages. Firstly, fresh air cannot be introduced into the apartments. Secondly, due to low temperature air discharge at approximately $4^{\circ} \mathrm{C}$, the system cannot be installed into rooms with small surfaces. Furthermore, these systems have a high energy demand.

Therefore, a new installation system is to be designed in order to facilitate centralized ventilation and conditioning of the apartments. Using TRaNsient System Simulation (TRNSYS) software, variations of indooroutdoor temperature, cooling loads and energy consumption of two alternative systems have been studied. 


\subsection{Overall solution description}

Currently The new installation systems is designed to offer both the necessary fresh air supply within the apartment during the year as well as the required energy demand for conditioning during the summer. The system consists of a Canadian shaft, a plate heat recovering system, an adiabatic cooling system and the piping network (see Fig. 4).

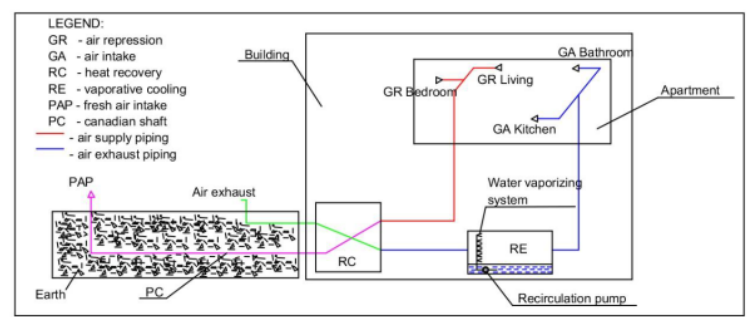

Fig. 3. Ventilation/cooling system diagram.

The running principle is as follows: fresh air is captured through an intake. Due to the low temperature of the soil, by flowing through the "Canandian shaft" the air is cooled and introduced into the heat recovery system where the second cooling phase starts. The cooling results as a consequence of the evacuated foul air being cooled down to the wet bulb temperature, by the water spraying equipment (adiabatic cooling = evaporative cooling). Therefore, the two air flows reach the heat recovering system, but do not mix together, and the fresh air is cooled. Fresh air is introduced in living room and sleeping areas and the foul air is evacuated from the kitchens and bathrooms. The tubing for the introduced air is to be mounted on the building façade and the ones for foul air within the existing plumbing shafts located in the bathrooms and kitchens. The tubing will be periodically checked for maintenance. The equipment for this cooling and ventilation system will be placed on the basement level of the building.

\section{Dimensioning of the composing elements of the ventilating and air conditioning system}

\subsection{Determining the air flow for ventilation and air conditioning}

To determine the needed air flow for ventilation and air conditioning of the spaces, the thermo-humidity ratio needs to be obtained (the process area) $\varepsilon$, in $\mathrm{kJ} / \mathrm{kg}$ :

$$
\varepsilon=\frac{Q_{r a c}}{G_{v}}
$$

where: $G_{v}$ is the humidity yield of the space, in $\mathrm{kg} / \mathrm{s} ; Q_{r a c}$ - the thermal cooling yield, in $\mathrm{kW}$.

For the humidity yield, it has been considered that there are 2 adults and 2 children inhabiting the apartments, and that the exhaust of humidity per person is $0,135 \mathrm{~kg} / \mathrm{h}$. The general relation of the mass air flow $L$ in $\mathrm{kg} / \mathrm{s}$, has the expression:

$$
L=\frac{Q_{\text {rac }}}{i_{i}-i_{R}}
$$

where: $i_{i}, i_{R}$ are the enthalpy of the interior air and the repressed air respectively, in $\mathrm{kJ} / \mathrm{kg} ; Q_{\text {rac }}$ - cooling thermal yield, in $\mathrm{kW}$. For determining the enthalpy of the repressed air $i_{R}$, in the Moliere diagram, a parallel line from point I (the interior air state) to $\varepsilon$ is intersected with the imposed isotherm of the repressed air $t_{R}$.

The state parameters of the interior air I were chosen according to the ambiental comfort levels, as follows: the interior temperature of $t_{i}=26^{\circ} \mathrm{C}$ and relative humidity of $\varphi_{i}=60 \%$. For these values, an enthalpy of the interior air of $i_{i}=58,4 \mathrm{~kJ} / \mathrm{kg}$ was obtained.

\subsection{Determining the thermal balance during the summer}

The thermal balance during summer for ventilated/cooled rooms in "up-down" system allows to calculate the thermal load in $\mathrm{W}$, using the formula:

$$
Q_{r a c}=Q_{a p}+Q_{d e g}
$$

where: $Q_{a p}$ represents the heat input from the outside and $Q_{\text {deg }}$ the heat dissipation from the interior sources.

Because the interior heat dissipation sources generally have a constant intensity, the cooling thermal load is maximal when the heat input from the outside is maximum. The outside heat input is defined in [W] using the following equation:

$$
Q_{a p}=Q_{p e}+Q_{f e}+Q_{i v}
$$

where: $Q_{p e}$ is the heat input from the outside through inertial elements such as wall or slabs; $Q_{f e}$ - the heat input through non-inertial elements such as windows and $Q_{i v}$ - the heat flux through the separation elements between rooms

The heat dissipation $Q_{d e g}$ of the interior sources is calculated using:

$$
\begin{gathered}
Q_{d e g}=Q_{0}+Q_{i l}+Q_{m} \\
Q_{0}=N q_{0} ; \quad Q_{i l}=B P_{i l} ; \quad Q_{m}=\Psi P_{m}
\end{gathered}
$$

where: $Q_{0}$ represents the heat dissipated by the human body; $Q_{i l}$ - heat dissipation from electric sources; $Q_{m}$ heat dissipation from equipment and other machinery powered by electricity; $N$ - the number of people within a specific room; $q_{0}$ - heat dissipation from a person influenced by physical effort and the indoor air temperature; $P_{i l}$ - electrical power of the lighting sources; $B$ - a coefficient that takes into account the electric energy transformation into heat (for ,up-down” ventilation, a value of 1,1 is considered); $P_{m}$-installed power or electric powered; $\Psi$ value coefficient between $0,12 \ldots 0,16$. 
Using the above explained method, a maximal value of $2.4 \mathrm{~kW}$ for the thermal balance during summer has been obtained. By applying equations (4.1) and (4.2) a value of $1125 \mathrm{~m}^{3} / \mathrm{h}$ for the airflow, needed for ventilation and cooling of the apartment, has been achieved.

\subsection{Determining the "Canadian Shaft" in TRANSYS}

The Canadian shaft systems is a ventilation system conceived to pre-heat or cool the fresh air introduced in buildings, using the heat and thermal inertia of the ground, due to its relatively constant temperature throughout the year, at a certain depth. The system circulates an outdoor air flow through a buried coil of piping over a length of $100 \mathrm{~m}$ and a depth of $2 \mathrm{~m}$, situated in the courtyards of the collective dwellings, and introduces the pre-cooled air inside the apartments. The air circulation through the piping is accelerated by the fan mounted on the heat recovering unit, assuring the above determined air flow.

During summer the soil temperature is lower than the exterior temperature. Using this lower temperature, the air is cooled. By the time the air reaches the interior spaces, it has a temperature value of $18^{\circ} \mathrm{C}-22^{\circ} \mathrm{C}$, depending on the temperature of the outside air. For an efficient use on the "Canadian shaft" a automation of the installation system is required based on the indoor temperature in order to avoid increasing relative humidity values and for eliminating the warm air to the outside.

The heat exchange between air and soil depends on their thermal properties. The main characteristics which influence the air-soil heat exchange are thermal conductivity $(\lambda)$, specific heat $(c p)$, density $(\rho)$ and soil temperature $(t)$

The main thermal properties of the soil are conditioned by its structure and they vary for same 1 types of soil depending of the humidity. The soil temperature at a depth of $2 \mathrm{~m}$ is approximately $17^{\circ} \mathrm{C}$ during summer.

For an optimal heat exchange, the flow speed of the air inside the tubing should be between 0,5 and $4 \mathrm{~m} / \mathrm{s}$. For high flow circulations a circulation speed of 2,5 - 4 $\mathrm{m} / \mathrm{s}$ is recommended. The air intake will have a filter and fixed frame shutters for protection against rain and a grill to prevent foreign objects for getting in.

Having a $1125 \mathrm{~m}^{3} / \mathrm{h}$ air flow, a $3,9 \mathrm{~m} / \mathrm{s}$ flow speed is induced on the tubing, resulting a $315 \mathrm{~mm}$ tubing crosssection for the intake, while on the exhaust, the air speed can record speeds up to $6,2 \mathrm{~m} / \mathrm{s}$, resulting in diameters of the tubes of $250 \mathrm{~mm}$.

The thermal performance of this system is defined as a ratio between the difference in realized temperature and the maximum possible temperature difference.

$$
\eta=\frac{T_{1}-T_{2}}{T_{1}-T_{S}}
$$

where: $T_{1}$ - exterior air temperature that enters the system; $T_{2}$ - air temperature the moment it leaves the systems; $T_{S}$ - soil temperature.

To simulate the "Canadian Shaft" in TRNSYS, a component Type 952 has been used. The component has all the parameters for the soil characteristics defined as well as the length, diameter and depth of the underground piping. As input data for the capture air, type 15 "Weather data database" has been used.

\subsection{Determining the heat recovery system in TRANSYS}

Heat recovery systems within ventilation and cooling networks reduce the energy loss from the outgoing air to a minimum. In order to be functional, the heat recovery battery needs to meet the following requirements: high efficiency, air tightness, decent freezing sensitivity, moderate load losses, high corrosion resistance and easy maintenance.

Constructively, heat recovery systems are rotative, with plates, thermal tubes and intermediate fluid. In the present case, a recuperative system has been used, using an exchange surface for the heat transfer and only transmitting sensitive heat (plate heat recovery unit) (Fig. 5).

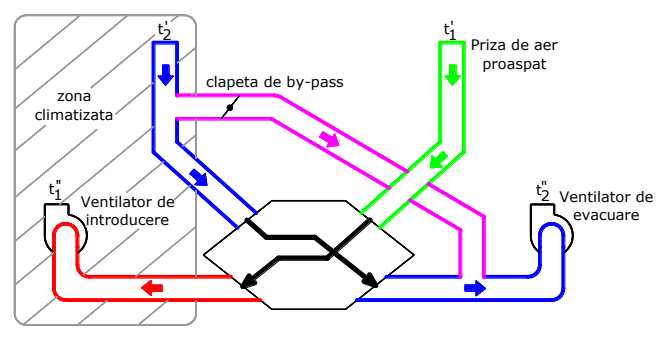

Fig. 4. Plate heat recovery unit diagram.

The heat exchange performance, in $\%$, for the plate heat recovery units, is defined as follows:

$$
\eta_{R C}=\frac{t_{1}^{\prime \prime}-t_{1}^{\prime}}{t_{2}^{\prime}-t_{1}^{\prime}} 100
$$

The thermal performance of the heat recovery unit represents how much of the available temperature difference can be used in the heat recovery process. When the fluid flows (masic flow multiplied with the specific heat) are equal on both sides of the heat recovery unit, then the performance of the cold side is equal to the performance of the cold side. For determining the heat transfer, the decrease in pressure is to be considered. When all the air flows, performances and temperatures are known, the quantity of heat transferred from the hot side to the cold one can be determined as follows:

$$
q_{R C}=\eta_{R C} L c_{p a}\left(t_{2}^{\prime}-t_{2}^{\prime \prime}\right)
$$

where: $q_{R C}$ is the quantity of recoverable heat; $L$ - mass air flow; $c_{p a}$ - specific heat of the air; $\eta_{R C}$ - performance of the heat recovery unit. 
In the case of rotative heat recovery units, where both sensitive and latent heat are recovered, in the hypothesis that the air flows are equal, the general relation of the performance $\eta_{R C}$, in $\%$, of the heat recovery unit is:

$$
\eta_{R C}=\frac{i_{a 1}^{\prime \prime}-i_{a 1}^{\prime}}{i_{a 2}^{\prime}-i_{a 1}^{\prime}} 100
$$

For the introduction of the heat recovery unit in TRNSYS, the element type has been used, with the parameters of electric power of the fans and the on/off command according to the function for the interior temperature, controlled in TRNSYS by controller type 108. The entry data are the exit data of type 952, and the air state at the exit from the heat recovery unit are entry data for type 56, simulating a single apartment in a multizone building.

\subsection{TRNSYS simulation of evaporative cooling equipment for the exhaust air from the apartment and introduced in the heat recovery unit}

The evaporative cooling equipment is modelled using Type 507 component, for which the user introduces the initial state of the air entering the water curtain and sets the preferred relative humidity of the air upon exit. The cooling process is realized by keeping a constant wet bulb temperature.

The air exiting the water curtain has a lower temperature and a higher 360 relative humidity. When the air enters the fog-forming device and the entry signal is active $(\mathrm{ON})$, Type 507 component runs subroutine PSYCHOMETRICS for determining the state of the admission air (temperature of the wet thermometer, enthalpy).

The thermal power $Q_{a e r}$, in $\mathrm{kJ} / \mathrm{h}$, extracted from the air flow for evaporating the water, in these conditions, is determined by:

$$
Q_{a e r}=L\left(i_{a i}-i_{a e}\right)
$$

where: $L$ is the air flow passing through the fog curtain, in $\mathrm{kg} / \mathrm{h} ; i_{a i}, i_{a e}$ - air enthalpy and the entrance exit from the equipment, in $\mathrm{kJ} / \mathrm{kg}$.

All components have been interconnected using subroutine Simulation Studio from TRNSYS, according to the diagram in Figure 6.

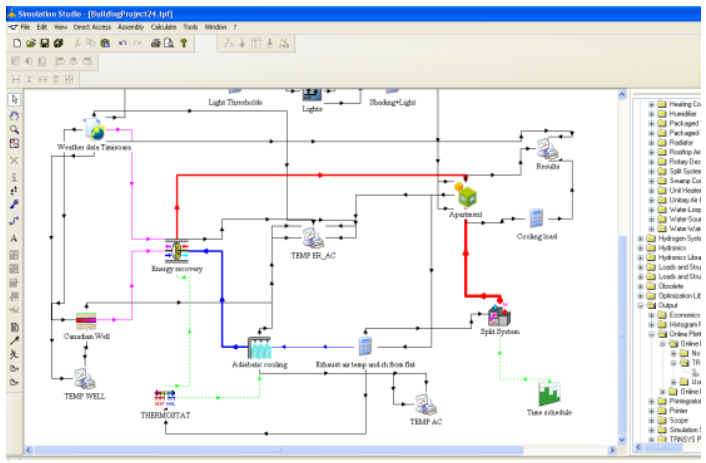

Fig. 5. Functional diagram in TRNSYS.

\section{Results and conclusions}

\subsection{Solar radiation intensity, outdoor temperature and thermal cooling load simulation}

\subsubsection{Indoor-outdoor temperature and solar radiation}

When no system is operating inside the apartment, the higher the intensity of the solar radiation is, the higher the tendency of the interior temperature to increase (see Fig. 7).

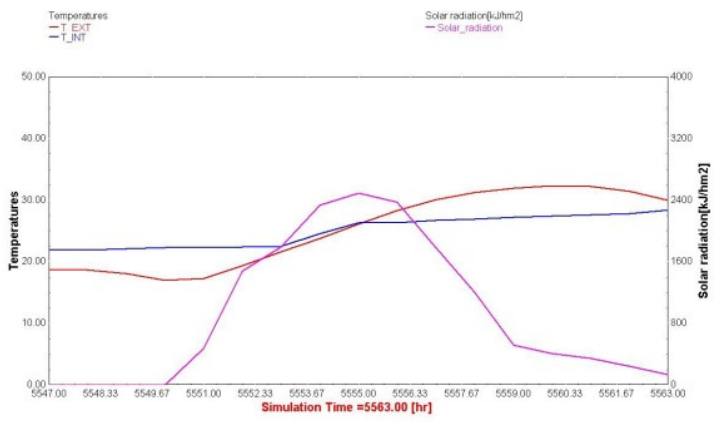

Fig. 6. Indoor-outdoor temperature and solar radiation.

The intensity of the solar radiation has a maximal value of $2495 \mathrm{~kJ} / \mathrm{hm}^{2}$. At that moment the indoor and outdoor temperatures are equal, both having $26^{\circ} \mathrm{C}$ (simulation time 5554=10.00 a.m.).

The maximal values for the exterior and interior are recorded at simulation time $5559=03.00$ p.m., $32,35^{\circ} \mathrm{C}$ and $27,5^{\circ} \mathrm{C}$ respectively.

\subsubsection{Exterior temperature and cooling load}

At simulation time $5558=02.00$ p.m. the maximal value for the cooling load is registered, $Q_{r a c}=8605 \mathrm{~kJ} / \mathrm{h}=2,4$ $\mathrm{kW}$. After a $1 \mathrm{~h}$ time span (simulation time 5559) the maximal value for the exterior temperature is reached $t_{e}=32,35^{\circ} \mathrm{C}$ (see Fig. 8), and at 5554 the maxima value for the solar radiation intensity, $I=2495 \mathrm{~kJ} / \mathrm{hm}^{2}$ (see Fig. 9).

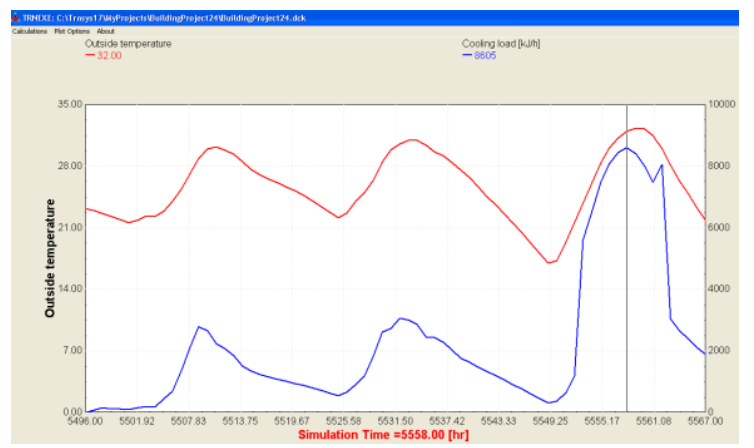

Fig. 7. Outdoor temperature and cooling load.

It can be seen that the construction elements, due to their thermal inertia, generate a $4 \mathrm{~h}$ phase lag between the intensity of the solar radiation and the cooling load. 
Furthermore, both of them have similar curvatures, with the cooling load being slightly sharper at the upper end.

Also, for the studied building, the variation of the intensity of the solar radiation compared to the variation of the outdoor air has the higher influence.

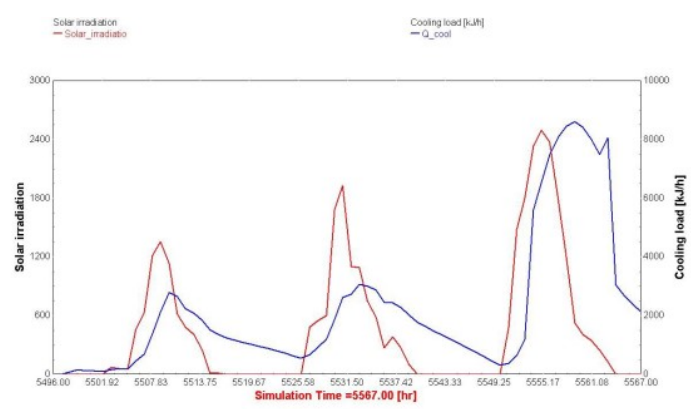

Fig. 8. Solar radiation intensity and cooling load.

\subsection{Canadian shaft temperature variations}

For the chosen "Canadian shaft" the minimum difference between the outdoor temperature and the exit temperature is $2,2^{\circ} \mathrm{C}$, recorded at simulation time 5549 , while the maximum difference is $6,03^{\circ} \mathrm{C}$, simulation time 5559, when $t_{e}=32,35^{\circ} \mathrm{C}$ and tiesire put $=26,33^{\circ} \mathrm{C}$ (see Fig. 10). The air transformation in the "Canadian shaft" is at a constant humidity level.

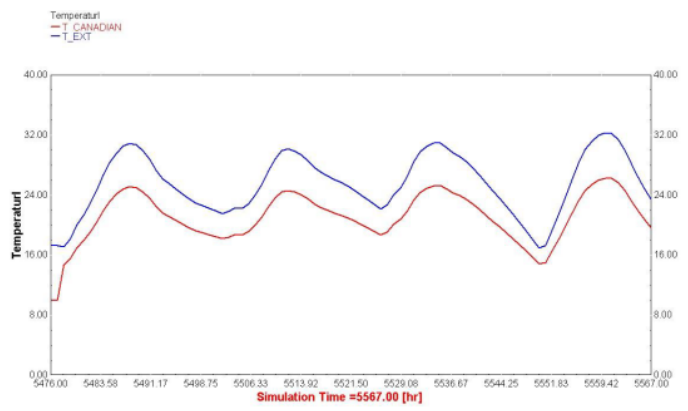

Fig. 9. In/out temperature variation.

Between simulation times 5553 (09.00 a.m.) and 5565 , the average value for the exterior temperature at entering and exiting the "Canadian shaft" have been calculated: te $\mathrm{m}=29,02^{\circ} \mathrm{C}$ and tiesire_put_m $=23,84^{\circ} \mathrm{C}$ respectively.

\subsection{Adiabatic cooling}

Figure 11 shows that the adiabatic cooling method for the evacuated air happens until the relative humidity reaches $95 \%$. The lower the humidity of the evacuated air is the lower the temperature gets.

At simulation time 5563 the maximal temperature difference $\left(5,48^{\circ} \mathrm{C}\right)$ is recorded. Therefore, if the air is eliminated from the apartment at a temperature of $23,64^{\circ} \mathrm{C}$ and humidity of $10,2 \mathrm{~g} / \mathrm{kg}$, the air cools itself until it reaches $18,16^{\circ} \mathrm{C}$. Figure 11 also shows the operating hours of the adiabatic cooling system (7-8h for a $24 \mathrm{~h}$ cycle) which is controlled by a thermostat that keeps the interior temperature at $24^{\circ} \mathrm{C}$. This shear operating program reduces the electric energy consumption of the ventilation/cooling system.

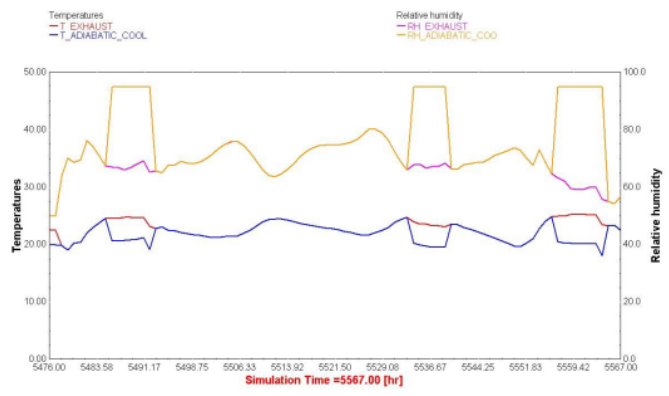

Fig. 10. Variation of the temperature and relative humidity of the air before and after the adiabatic cooling process.

\subsection{Heat recovery system (energy)}

In Figure 12 the values of the following temperatures are shown:

- the temperature of the eliminated air from the apartment (bathroom and kitchen);

- the temperature after the adiabatic cooling system;

- $\quad$ the temperature after the heat recover system (energy) is introduced in the apartment;

- the temperature at the exit point of the "Canadian shaft";

- $\quad$ the exterior temperature.

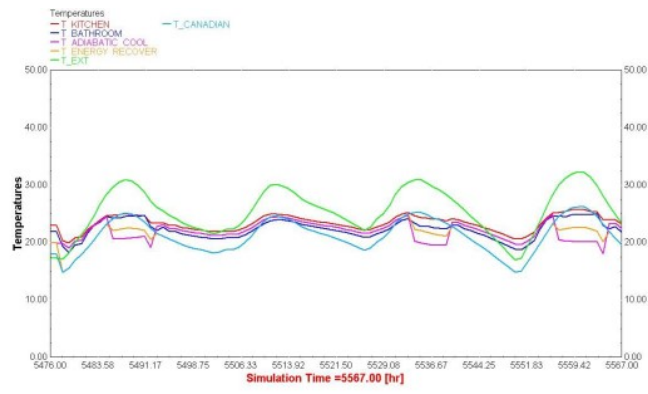

Fig. 11. Temperature variation for the whole proposed ventilation/cooling system.

At simulation time 5559, when the maximal value for the exterior temperature is recorded $\left(t_{e}=32,35\right)$, and after the air treatment through all of the systems components, the temperature value after the energy recovering system (that is to be introduced in the apartment) of $22,72^{\circ} \mathrm{C}$. The exterior temperature drops by $9,63^{\circ} \mathrm{C}$ and in the same time the eliminated air temperature is $25,05^{\circ} \mathrm{C}$.

\subsection{Results of the electric consumption simulations of the studied systems}

\subsubsection{Electric energy consumption for the conventional splits type system}

For the "splits type" system the running program is between simulation time 5560 (04.00 p.m.) and 5565 (09.00 p.m.) on August 18th. During this timeframe the total electric energy consumption of the fans on the indoor and outdoor unit together with the compressor is $6,37 \mathrm{kWh} /$ day. It was considered that the "splits" system 
runs 15 days for the month of August, reaching a total monthly consumption value of $95,62 \mathrm{kWh}$.

Starting from the graphic (see Fig. 13), considering the temperatures in the apartment, it can be seen that the values have a constant increase from the moment the system starts to run. The highest value is recorded in the bathroom, $29^{\circ} \mathrm{C}$ and in the kitchen, $28^{\circ} \mathrm{C}$. After 04.00 p.m. when the system starts running, the temperatures start to gradually drop to $24^{\circ} \mathrm{C}$

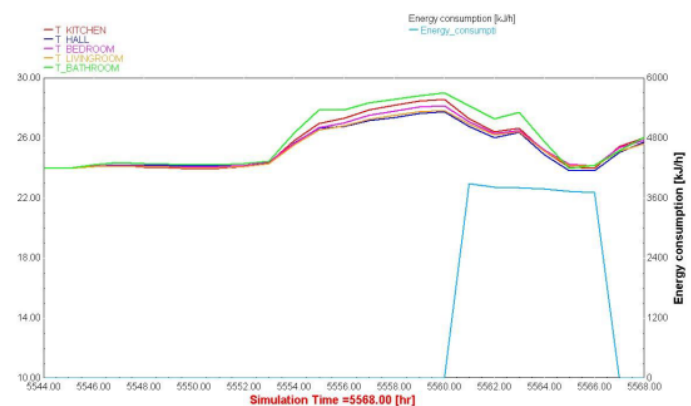

Fig. 12. Electric energy consumption for ,splits” type system.

\subsubsection{Electric energy consumption for the proposed cooling/ventilation system}

For the cooling/ventilation system based on "Canadian shaft", heat recovery system and adiabatic cooling installation, the running program for a $24 \mathrm{~h}$ timeframe is from simulation time 5555 (11.00 a.m.) till 5563 (07.00 p.m.) (see Fig. 14).

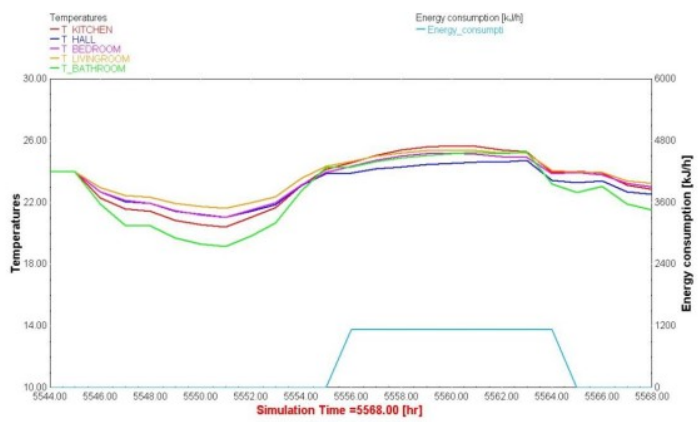

Fig. 13. Electric energy consumption for the proposed cooling/ventilation system.

During this timeframe, the total electric energy consumption of the 441 fans on the heat recovery system and the recirculation and vaporization pump for adiabatic cooling is $2,84 \mathrm{kWh} /$ day. If the same scenario as the previous one is to be considered, the monthly consumption value reaches $42,58 \mathrm{kWh}$. If the two studied systems are compared, the proposed system has e $55,47 \%$ energy consumption reduction. Analysing the graph by indoor temperature, it can be seen that values are between $23^{\circ} \mathrm{C}$ and $25^{\circ} \mathrm{C}$.

This work was supported by a grant of the Romanian Ministery of Research and Innovation, CCCDI - UEFISCDI, project number PN-III-P1-1.2-PCCDI-2017-0391 / CIA_CLIM Smart buildings adaptable to the climate change effects, within PNCDI III.

\section{References}

1. A. Botici., V. Ungureanu., A. Ciutina, A. Botici, D. Dubina., Sustainable Retrofitting of Large Prefabricated Concrete Residential Buildings, Central Europe towards Sustainable Building, 2013.

2. L. A. Fülöp, M.J. Riihimäki, Opportunities in Sustainably Retrofitting the Large Panel Reinforced Concrete Building Stock in East Europe, Opportunities and challenges in sustainably retrofitting the large panel concrete building stock, 2014, pp. 1-8, Orizonturi Universitare Press, Timisoara, Romania.

3. S.S. Lewin, C. Goodman, Transformative Renewal and Urban Sustainability. Journal of Green Building: Fall 456 2013, Vol. 8, No. 4, pp. 17-38.

4. National Institute of Statistics, "People and Housing Census", 2002

5. M. Economidou. \& all. (2011). Europe's Buildings under the Microscope - A Country-by-Country Review of the Energy Performance of Buildings: 26-53, BPIE: Buildings Performance Institute of Europe, 2011 pp. 98122.

6. *** IPCT, Cladiri de locuit $\mathrm{P}+4$ din panouri mari. Proiect 770-81, Vol. D: Elemente prefabricate si armari, (Precast reinforced concrete large panel collective dwellings P+4. Project 770-81, Vol. D: Precast elements - Reinforcing), Volume D, Bucharest, Romania, 1981 (in Romanian).

7. Todut, V. Stoian, I. Demeter, T. Nagy-György, V. Ungureanu, Retrofitting of earthquake damaged precastconcrete wall using FRP composites, fib Symposium 2013 - Engineering a Concrete Future: Technology, Modeling \& Construction, 573-576, 2013.

8. M. Popov, M. Szitar, M. Sămânță, An Integrated Approach - Retrofitting the Blocks of Flats Made of Prefabricated Panels, Opportunities and challenges in sustainably retrofitting the large panel concrete building stock, 2014, pp. 131-144, Orizonturi Universitare Press, Timisoara, Romania.

9. M. Popov, Reabilitarea integrate a locuintelor collective din panouri mari prefabricate. Solutii structurale (Integrated Retrofitting of Large Prefabricated Panels Collective Dwellings. Structural Solutions), PhD Thesis, 2015, Editura Politehnica, Timsoara, Romania (in Romanian).

10. ***, P100-1:2013, Cod de proiectare seismică (Seismic design code. Part I - Design previsions forbuildings), Monitorul Oficial al României (Official Journal of Romania), Part 1, No. 803 bis, 2006 (in Romanian). 